\title{
Academic Dishonesty among Undergraduate Nursing Students
}

\section{Cavelle Allen*, Shaulene Stanley, Karozan Cascoe and Rosain Stennett}

The UWI School of Nursing, Mona, The University of the West Indies, Jamaica

*Corresponding author: Cavelle Allen, The UWI School of Nursing, Mona, The University of the West Indies, Mona, Kingston 7, Jamaica, E-mail: cavelle.walters02@uwimona.edu.jm

\section{Introduction}

Academic dishonesty amongst nursing students has become a common occurrence and has drawn a great amount of public scrutiny in recent times [1-3]. This is often viewed as the starting point of legal agitation to nursing educators because of the possible impact this will have on existing and subsequent professional practice and patient care [4]. To be able to reduce academic dishonesty effectively, an understanding of the underlying issues is crucial.

Academic dishonesty is defined as a student's intentional attempt to falsify, fabricate or tamper with data, information, records, or any other material that is relevant to any course, laboratory, or other academic exercise or function [5]. Additionally, academic dishonesty can take many forms in both the clinical and classroom settings. These include cheating in examinations and/ or committing plagiarism and forgery, resulting in the student not obtaining the expected knowledge $[2,6]$. For the profession of nursing, academic dishonesty also extends to the clinical activities of nursing students in the clinical setting and this is evidenced by signing the clinical register but not reporting for duty or leaving the assigned shift early but signing the normal time. Other acts of dishonesty also include charting care not done and stealing patients' medication $[1,6]$.

Academic dishonesty has been a long standing phenomenon that has been frowned upon since as far back to the time of the Greek philosopher Aristotle who wrote that "ethical codes had to be embodied in a code of law interconnected with the whole framework of social and political systems and that young citizens had to learn these laws in order to live the life of citizens and of individuals following accepted standards of right and wrong" [7].
Since the inception of institutions of higher education academic dishonesty remains prevalent. McCabe, Trevino and Butterfield (2001) as cited by Klocko [8] described a steady rise in academic dishonesty in higher education across all discplines. Interestingly, McCabe [4] suggested that there was no unusual difference between the occurrences of cheating behaviours (a common manifestation of academic dishonesty) in nursing programs, compared with other disciplines. Of note, cheating in nursing programmes is common and supported by literature $[2,3,9]$.

Ethical practice and academic integrity derived from honesty should form the bedrock of any nursing education environment. This foundation is crucial to quality patient care and outcomes. Honesty is regarded as a basic ethical value and academic integrity is vital in the educational environment. In the nursing profession, it is especially important as the well-being of the patients in our care depend on it [5]. In 2006 Gallup poll, it was revealed that nursing was seen as the most honest of 23 professions and the one with the highest ethical standards [10]. With such a high ethical expectation of the profession, one would assume that academic dishonesty would be non-existent in nursing programs. However, it has been documented that a vast number of nursing students participate in academically dishonest behaviours [5]. Therefore, the threat exists when these unethical behaviours displayed as academic dishonesty are transferred to the nursing practice environment because they often translate into harmful patient outcomes $[3,5,8]$. For this reason, there should be a clear message of zero tolerance for such behaviour at all levels.

\section{Factors Influencing Academic Dishonesty}

A research conducted in 2010 at a nursing educa-

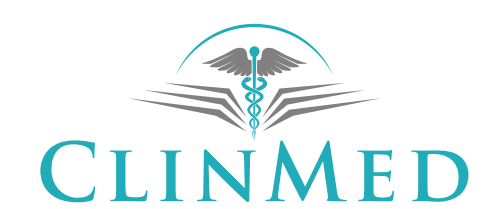

INTERNATIONAL LIBRARY

Citation: Allen C, Stanley S, Cascoe K, Stennett R (2017) Academic Dishonesty among Undergraduate Nursing Students. Int Arch Nurs Health Care 3:074. doi.org/10.23937/2469-5823/1510074 Received: April 22, 2017: Accepted: July 13, 2017: Published: July 15, 2017

Copyright: (C) 2017 Allen C, et al. This is an open-access article distributed under the terms of the Creative Commons Attribution License, which permits unrestricted use, distribution, and reproduction in any medium, provided the original author and source are credited. 
tion institution in Western Cape Town, South Africa, sought to explore academic integrity among 550 nursing students. It was discovered that majority (88\%) of the respondents admitted to have committed at least one form of academic dishonesty [5]. Within the same study, it was discovered that some of the factors that influenced academic dishonesty include gender, pressure to succeed academically (84\%), limited time available to study (74\%), fear of losing status among peers (71\%) and the impact of successful cheating (71\%) [5]. Interestingly, majority of the respondents indicated that they had knowledge of the institution's policies regarding referencing of sources, conduct in examination venues and the consequences of academic dishonesty but were more familiar with policies that guided their conduct in the venues than the referencing of sources [5]. Similarly, Kolanko, et al. [11] in their study, discovered that academic pressure such as competition for higher grades, honours, awards, and a grade point average sufficient for graduate study, contributed significantly to students' engagement in acts of academic dishonesty.

Some researchers have indicated that in some cases, there is uncertainty as to what actions constitute academic dishonesty $[2,3,9]$. Though students indicate that they have engaged in the act of having access to examination paper, or falsify information on medication records, students sometimes believe that this is acceptable due to a lack of knowledge, poor practice behaviour and pressure to succeed and complete assigned tasks.

Klocko [8] mentioned that there were individual factors, contextual factors and students' attitudes towards cheating, which influenced a student's decision to cheat. The individual factors consist of personality traits such as irresponsibility, laziness and poor self-image. Contextual factors involve environmental influences such as parental pressure and poor preparation for examinations. Furthermore, the importance of precision in nursing practice, lack of moral growth, engaging in daring behaviours which students rely on not being caught or punished, the will to be successful by any means, lack of preparation or skills, poor academic standing, poor grades, and concerns about the financial impact of failing a course, were all highlighted as influential toward the acts of academic dishonesty. Time management factors and competing assignments, a classroom or clinical environment that contributed to academically dishonest behaviours and the use of rationalizations to justify dishonest actions, were also noted as influential factors regarding academic dishonesty [11].

Additionally, Klocko [8] mentioned that with the increase usage of online courses in higher education, cheating was much harder to detect than the face to face setting of a classroom. Also, with the rise of the technological era, students are finding it easier to misuse cell phones, $\mathrm{mp} 3$ devices, tablets and the internet in general to communicate during examinations, surf the internet when it is against examination policy and plagiarizing through cutting and pasting information and presenting it as their own work [10].

\section{Implications of Students' Engagement in Acts of Academic Dishonesty}

Despite the worrying incidence of academic dishonesty and concerns within higher education for centuries, colleges and universities have not yet been able to develop strategies to abate academic dishonesty [1]. The embracing of the professional codes of conduct is welcomed by society as a foundation of nursing practice and a promise of quality services [12]. However, students', particularly, nursing students' engagement in academic dishonesty has many implications for the profession of nursing as it relies heavily on the moral integrity of its members. The consequence of these undesired behaviours violates trust in the nursing profession to appropriately value human life and care for patients with honesty. It was found that student nurses who were academically dishonest were more likely to commit dishonest acts in clinical practice and this can often translate into harmful patient outcomes $[1,3,5,8]$.

\section{Recommendations to Address the Issues of Academic Dishonesty}

In Universities, standards are set to prevent such behaviours from occurring. The students' handbook is one such standard that outlines the behaviours and acts that warrant suspension or dismissal [13]. Smedley, Crawford and Cloete, [9] suggested numerous ways to reduce academic dishonesty. These include ensuring and preserving a trustworthy environment, conveying clear values and beliefs, an environment of trust, communicating clear expectations, speaking up when academic misconduct occurs and reinforcing the University principles on academic integrity and professional behaviour. Students will not pursue academic dishonesty if there is a high likelihood of being identified and recognized.

Once academic dishonesty and misconduct is identified, stringent action needs to be taken along with strict penalty so that the act may serve as a deterrent for other students. In addition, schools need to create policies that clearly define behaviours, processes, and consequences to guide the implementation of specific cheating and other acts of academic dishonesty preventive strategies [14]. Technology has been used to assist in refraining those who may be tempted to cheat/plagiarize, using sites such as "Turnitin" or "SafeAssign" where academic papers are edited and checked. The use of e mail to interact with students and paying keen attention to their writing styles, will give the educators an idea of the students writing styles thus allowing the instructor to a chance to identify and discern changes in the student's quality of work. Going forward, additional research is needed to focus on finding effective strategies to counteract academic dishonesty among nursing students in 
both the classroom and clinical settings. Also, exploring the role of the nurse educator in communicating and fostering/modelling good ethical practice in nursing students.

\section{References}

1. Johnson JA (2013) Does academic dishonesty result in unethical professional practice? J Nurses Prof Dev 29: 271273.

2. Krueger $L$ (2014) Academic dishonesty among nursing students. J Nurs Educ 53: 77-87.

3. Macale L, Ghezzi V, Rocco G, Fida R, Vellone E, et al. (2017) Academic dishonesty among Italian nursing students: A longitudinal study. Nurse Educ Today 50: 57-61.

4. McCabe DL (2009) Academic Dishonesty in Nursing Schools: An Empirical Investigation. J Nurs Educ 48: 614-623.

5. Theart CJ, Smit I (2012) The status of academic integrity amongst nursing students at a nursing education institution in the Western Cape. Curationis 35: 27.

6. Kyzer TE (2010) An exploration of academic dishonesty at the community college level.

7. Russo CJ (2010) Encyclopedia of Law and Higher Education. Sage Publications, Washington, DC.
8. Klocko MN (2014) Academic dishonesty in schools of nursing: A literature review. J Nurs Educ 53: 121-125.

9. Smedley A, Crawford T, Cloete L (2015) An intervention aimed at reducing plagiarism in undergraduate nursing students. Nurse Educ Pract 15: 168-173.

10. Arhin A, Jones F (2009) A multidiscipline exploration of college students' perceptions of academic dishonesty: are nursing students different from other college students? Nurse Educ Today 29: 710-714.

11. Kolanko KM, Clark C, Heinrich KT, Olive D, Serembus JF, et al. (2006) Academic dishonesty, bullying, incivility, and violence: Difficult challenges facing nurse educators. Nurs Educ Perspect 27: 34-43.

12. McCrink A (2010) Academic misconduct in nursing students: behaviors, attitudes, rationalizations, and cultural identity. J Nurs Educ 49: 653-659.

13. Robson C, McCartan K (2016) Real World Research: A resource for users of social research methods in applied settings. ( $4^{\text {th }}$ edn), Wiley \& Son Limited, Chichester, West Sussex.

14. Stonecypher K, Willson P (2014) Academic policies and practices to deter heating in nursing education. Nurs Educ Perspect 35: 167-179. 